\title{
Maternal and Social Factors Associated with Abortion In India: A Population-Based Study
}

By Saseendran Pallikadavath and R. William Stones

Saseendran Pallikadavath is senior research fellow, Centre for AIDS Research, and $R$. William Stones is director, Centre for

AIDS Research, and senior lecturer, Department of Obstetrics and

Gynecology-both at the University of Southampton, United Kingdom.
CONTEXT: A cultural preference for sons may be a factor driving recourse to abortion in India, as women carrying female fetuses may decide to terminate their pregnancies. To assess this hypothesis, more information on the incidence of abortion, and on maternal and social correlates of the procedure, is needed.

METHODS: Birth order-specific abortion ratios were calculated using the birth histories of 90,303 ever-married women aged 15-49 who participated in India's 1998-1999 National Family Health Survey. For the first four births, the association between abortion and various maternal and social variables, including the sex of the respondent's last child, was assessed using logistic regression.

RESULTS: The overall abortion ratio was 17.0 per 1,000 pregnancies. The ratio increased from 5.3 per 1,000 pregnancies for first-order births to $25.8 \mathrm{per}$ 1,000 pregnancies for third-order births and then declined. The strongest predictor of abortion was maternal education: Women with at least a primary education were more likely than those with no education to have had an abortion (odds ratios, 1.9-6.7). Rural residence was associated with a reduced likelihood of abortion (0.6). There was no association between the sex of a woman's previous child and the odds that she subsequently had an abortion.

CONCLUSION: At the national level, it is likely that unintended pregnancy, rather than the sex of the previous child, underlies demand for abortion in India. Rising educational attainment among women may lead to an increase in the demand for abortion.

International Family Planning Perspectives, 2006, 32(3):120-125
Under the 1971 Medical Termination of Pregnancy Act, a woman in India can legally obtain an abortion if her pregnancy carries the risk of grave physical injury, endangers her mental health, is the result of contraceptive failure (in a married woman) or rape, or is likely to produce a child with physical or mental abnormalities. ${ }^{1}$ Legal abortions may be obtained through more than 11,000 approved clinics. $^{2}$ Estimates of the number of abortions performed annually in India vary considerably, from 0.6 million to 6.7 million. ${ }^{3}$ The former is an official figure, whereas the latter is an estimate derived from a field study; the difference could be an indication of the extent of illegal abortion.

Although abortion has been legal in India for more than three decades, access to safe services remains limited for most women. For example, it has been estimated that nearly $90 \%$ of abortions in India are performed under potentially unsafe conditions in unapproved facilities, by providers ranging from qualified doctors to those without any training or qualifications. ${ }^{4}$ Women use these providers because there is a dearth of medical provision in most rural areas and because many women are unaware of or unable to travel to the safe facilities that do exist. There are no definitive studies linking maternal deaths to unsafe abortions in rural settings, but official statistics from 1998 suggest that about $9 \%$ of maternal deaths in rural India are due to complications of abortion. ${ }^{5}$ This figure, however, does not take into consideration the very large differences in maternal mortality between the country's northern and southern states, or the difficulty of identifying deaths that occur early in pregnancy, before women have come to the attention of maternal health services. The Medical Termination of Pregnancy Act was amended in 2002 and 2003 to improve women's access to safe abortion, in part by giving village committees (Panchayats) more input regarding health services, ${ }^{6}$ but the impact of these changes on the number and safety of abortions has not yet been evaluated.

In cultures where there is a strong preference for children of a particular sex and where prenatal sex identification techniques are widely accessible, abortion may be used for sex selection. ${ }^{7}$ This is thought to be an important reason why women seek abortion in India, ${ }^{8}$ particularly in areas where technologies that can determine the sex of a fetus are available. ${ }^{9}$ However, evidence from several small studies suggests that the reasons why women in India seek abortions are diverse. For example, a study conducted in Maharashtra found that the need to space children was the most-cited reason that adolescents had abortions; most of these young women did not have experience using contraceptives. ${ }^{10}$ Another study, in Tamil Nadu, showed that nonconsensual sex, sexual violence and women's inability to refuse their husband's sexual demands were the factors that most frequently led to unwanted pregnancy and abortion. ${ }^{11}$ 
Identifying these and other factors that lead to abortion has important policy implications. If a preference for sons is the main driver of induced abortion in India, then making contraceptive services widely available would have relatively little effect in reducing the demand for the procedure. However, if policymakers attribute too much importance to the role of sex preference, they may undermine programs that provide needed contraceptive services to couples who wish to limit their family size or postpone their next birth. To shed light on the factors that lead women in India to have abortions, the objectives of the present study are to calculate birth order-specific abortion ratios using nationally representative data and to examine the associations between abortion and various maternal and social variables, including the sex of a woman's last child.

\section{METHODS}

\section{Survey Instrument}

The data in this study are from the 1998-1999 National Family Health Survey (NFHS-2), in which a nationally representative, population-based sample of 90,303 ever-married women aged 15-49 were asked questions about their fertility, family planning, reproductive health, use of reproductive health services and nutritional status. The survey methodology has been reported in detail. ${ }^{12}$ The present analysis includes data from all Indian states, including Tripura, which was not included in the official NFHS-2 report because fieldwork in the area was delayed due to security issues.

The primary resource for the present study was the complete birth history that each participant provided. During data collection, interviewers sought details about respondents' induced abortions, miscarriages and stillbirths in the context of their birth history; this method is likely to enhance recall of these events. Interviewers were specially trained to ask questions that could help distinguish among induced abortions, miscarriages and stillbirths.

\section{Variables}

Independent variables included in our analysis were maternal age at the time of subsequent live birth, maternal age at marriage, the sex of the previous child, maternal education, standard of living, religion, caste and place of residence (urban or rural). These variables were selected on the basis of their known associations with reproductive outcomes in other settings and studies, and their capacity to discriminate between the influence of related but distinct domains such as caste and educational attainment. Maternal age at subsequent live birth refers to a woman's age at the birth that followed a particular birth, abortion, miscarriage or stillbirth. Respondents were not asked to state the age at which each of their births, abortions or miscarriages occurred; however, a woman's age at the time of a live birth could be calculated by subtracting the age of her child (which was recorded in the survey schedule) from her current age. Age at marriage refers to the age, in completed years, at which respondents first married, grouped into four categories: younger than 15, 15-19, 20-24, and 25 or older.

\begin{tabular}{|c|c|c|c|c|c|c|}
\hline \multirow[t]{2}{*}{ Birth order } & \multicolumn{5}{|c|}{ Birth outcome } & \multirow[t]{2}{*}{ Abortion ratiot } \\
\hline & All & Abortions & Stillbirths & Miscarriages & Births & \\
\hline Total & 295,720 & 5,040 & 6,241 & 14,366 & 270,073 & $17.04(16.5-17.5)$ \\
\hline 1 & 89,162 & 470 & 2,634 & 5,680 & 80,378 & $5.27(4.8-5.8)$ \\
\hline 2 & 73,479 & 1,270 & 1,352 & 3,409 & 67,448 & $17.28(16.4-18.3)$ \\
\hline 3 & 52,892 & 1,365 & 871 & 2,167 & 48,489 & $25.81(24.5-27.2)$ \\
\hline 4 & 33,864 & 848 & 569 & 1,305 & 31,142 & $25.04(23.4-26.7)$ \\
\hline 5 & 20,503 & 516 & 359 & 750 & 18,878 & $25.16(23.1-27.5)$ \\
\hline 6 & 12,118 & 258 & 206 & 494 & 11,160 & $21.29(18.8-24.1)$ \\
\hline 7 & 6,783 & 169 & 134 & 289 & 6,191 & $24.91(21.4-29.0)$ \\
\hline$\geq 8$ & 6,919 & 144 & 116 & 272 & 6,387 & $20.81(17.6-24.5)$ \\
\hline
\end{tabular}

Maternal education was categorized as none, primary, secondary or higher. The NFHS-2 report included a standard of living index, which was derived from such indicators as the household's water source and toilet facilities and whether the family owned irrigated land, livestock and various durable goods (e.g., car, refrigerator, sewing machine). Scores on the index were classified as low (36\% of households), medium (44\%) or high (18\%)* as per the original NFHS-2 report. The other demographic variables included in the analysis are self-explanatory.

Abortions that occurred between live births are said to have occurred during a closed birth interval, whereas abortions that were not followed by a live birth are classified as having occurred during an open birth interval.

\section{Estimation of Induced Abortion Ratios}

The abortion ratio was defined as the number of induced abortions per 1,000 pregnancies. Ratios were calculated for each birth order from one to seven; we calculated a single ratio for birth orders of eight or more, because the number of cases for birth orders higher than eight was extremely low. The ratio for first births includes all induced abortions that occurred before a respondent's first live birth; it also includes all induced abortions reported by women who had not yet had a live birth at the time of the survey. The denominator includes all first live births as well as all induced abortions, miscarriages and stillbirths that occurred before a first live birth. The ratio for second births includes all induced abortions that occurred after a woman's first live birth but before her second, as well as all abortions reported by women who had had one live birth but not a second (i.e., women in an open birth interval). A similar approach was taken for the remaining birth orders. If there were two or more induced abortions in a particular birth order, both were assigned that order. Similarly, twins were assigned the same birth order.

*Percentages do not total $100 \%$ due to rounding. 
TABLE 2. Adjusted odds ratios (and 95\% confidence intervals) from logistic regression analysis assessing associations between maternal and social characteristics and induced abortion during closed birth intervals, according to birth order

Characteristic Birthorder

\begin{tabular}{llll}
\cline { 2 - 3 } & 2 & 3 & 4 \\
\hline
\end{tabular}

Maternal age at marriage

$\begin{array}{lllll}<15 \text { (ref) } & 1.00 & 1.00 & 1.00 & 1.00\end{array}$

$\begin{array}{lllll}15-19 & 1.48(0.97-2.25) & 1.60(1.16-2.20)^{* *} & 1.23(0.89-1.69) & 1.01(0.68-1.48)\end{array}$

20-24 $0.89(0.52-1.51) \quad 2.22(1.56-3.16)^{* * *} \quad 1.48(0.99-2.22)^{*} \quad 0.74(0.40-1.35)$

$\begin{array}{lllll}\geq 25 & 1.01(0.49-2.05) & 2.38(1.45-3.90)^{* * *} & 2.07(1.40-4.12)^{*} & 0.39(0.06-2.42)\end{array}$

Maternal age at subsequent live birth

$\begin{array}{lllll}<20 \text { (ref) } & 1.00 & 1.00 & 1.00 & 1.00 \\ 20-29 & 2.19(1.63-2.92)^{* * *} & 2.02(1.59-2.56)^{* * *} & 1.02(0.72-1.46) & 2.56(0.78-8.42) \\ 230 & 2.44(0.97-6.15)^{*} & 2.04(1.33-3.11)^{* * *} & 1.33(0.80-2.20) & 6.30(1.84-21.62)\end{array}$

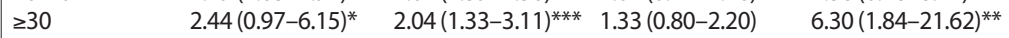

Sex of previous child

$\begin{array}{lllll}\text { Male (ref) } & \text { na } & 1.00 & 1.00 & 1.00 \\ \text { Female } & \text { na } & 0.96(0.83-1.11) & 0.92(0.76-1.13) & 0.90(0.67-1.22)\end{array}$

Maternal education

$\begin{array}{lllll}\text { None (ref) } & 1.00 & 1.00 & 1.00 & 1.00\end{array}$

Primary $\quad 1.58(1.08-2.32)^{* *} \quad 2.39(1.83-3.10)^{* * *} \quad 3.04(2.24-4.14)^{* * *} \quad 1.85(1.20-2.85)^{*}$

Secondary $\quad 2.27(1.60-3.21)^{* * *} 4.06(3.19-5.16)^{* * *} \quad 5.01(3.70-6.78)^{* * *} \quad 3.57(2.33-5.45)^{* * *}$

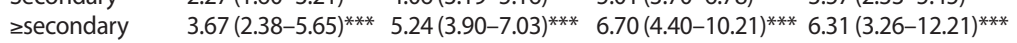

Standard of living

\begin{tabular}{|c|c|c|c|c|}
\hline \\
\hline Low (ref) & 1.00 & 1.00 & 1.00 & 1.00 \\
\hline Medium & $1.45(0.99-2.12)^{*}$ & $1.05(0.82-1.35)$ & $1.05(0.77-1.43)$ & $0.94(0.62-1.43)$ \\
\hline High & $1.38(0.88-2.14)$ & $1.31(0.99-1.73)$ & $1.32(0.92-1.88)$ & $1.55(0.94-2.56)$ \\
\hline \multicolumn{5}{|l|}{ Religion } \\
\hline Hindu (ref) & 1.00 & 1.00 & 1.00 & 1.00 \\
\hline Muslim & $1.10(0.77-1.56)$ & $0.72(0.55-0.95)^{* *}$ & $1.07(0.79-1.44)$ & $0.62(0.37-1.01)^{*}$ \\
\hline Other & $0.83(0.52-1.34)$ & $1.05(0.82-1.36)$ & $1.45(1.04-2.05)^{*}$ & $1.08(0.57-2.03)$ \\
\hline
\end{tabular}

Caste

Scheduled

$\begin{array}{llll}\text { caste (ref) } & 1.00 & 1.00 & 1.00\end{array}$

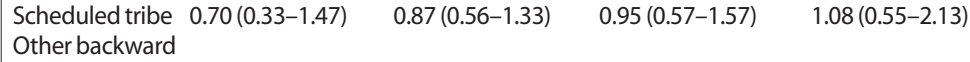

$\begin{array}{lllll}\text { class } & 1.11(0.73-1.67) & 1.17(0.90-1.51) & 0.97(0.71-1.39) & 0.98(0.61-1.58)\end{array}$

$\begin{array}{llll}\text { Other castes } \quad 1.32(0.89-1.97) & 1.13(0.88-1.46) & 1.04(0.75-1.44) & 1.19(0.74-1.88)\end{array}$

Residence

$\begin{array}{lllll}\text { Urban (ref) } & 1.00 & 1.00 & 1.00 & 1.00 \\ \text { Rural } & 0.60(0.46-0.78)^{* * *} & 0.55(0.48-0.66)^{* * * *} & 0.57(0.46-0.72)^{* * *} & 0.61(0.43-0.86)^{* *}\end{array}$

${ }^{*} \mathrm{p}<0.05 .{ }^{* *} \mathrm{p}<0.01 .{ }^{* * *}<0.001$. Notes: ref $=$ reference group. na=not applicable.

\section{Statistical Analysis}

We developed logistic regression models for each birth order up to four, beyond which the sample sizes for individual birth orders became too small to be informative. The dependent variable was whether or not a woman had an induced abortion within a given birth-order period. By definition, age at subsequent live birth was included only in analyses of closed birth intervals.

Because it is possible that the sex composition of all of a woman's living children, rather than the sex of the last child, influenced the decision to have an abortion, we also performed logistic regression analyses among women who had either all boys or all girls. Three separate logistic regressions were modeled, one each for parities 2-4.

We tested for multicollinearity among the independent variables; in no case was the tolerance value less than 0.2 or the variance inflation factor greater than 10 . There was no significant interaction between age at marriage and age at first birth.

\section{RESULTS}

\section{Abortion Ratio}

Overall, respondents had had 17.0 induced abortions per 1,000 pregnancies. Table 1 (page 121) shows all birth outcomes for each birth order, as well as the associated abortion ratios. The abortion ratio was lowest for the first birth order (5.3) and highest for the third birth order (25.8), after which it declined. The relationship between abortion ratio and birth order was nonlinear.

\section{Closed Birth Intervals}

Logistic regression revealed several factors associated with the odds of abortion during closed birth intervals (Table 2). The odds of abortion increased with women's age at marriage, but only for birth orders two and three. For example, for these birth orders, the odds of abortion among women who were 25 or older when they married were more than twice that of women who married before age 15 (odds ratios, 2.4 and 2.1, respectively).

In general, the odds of abortion increased with older maternal age at subsequent live birth. For birth order one, the odds of abortion among women whose subsequent birth occurred when they were 20 or older were more than twice the odds among women who were younger than 20 at their subsequent birth. The pattern was similar for birth orders two and four.

However, the sex of a respondent's previous child was not significantly associated with induced abortion in any birth order. Moreover, analyses comparing women who had all boys with those who had all girls found no significant differences in their odds of abortion (data not shown). For example, the likelihood of having had an abortion among women with three sons (odds ratio, 1.1; 95\% confidence interval, 0.9-1.4) was not significantly different from that among women with three daughters.

The variable that was most strongly and consistently associated with induced abortion was maternal education. The odds of abortion among women who had more than a secondary education were significantly higher than those among women with no education (odds ratios, 3.7-6.7); odds were intermediate for women with a primary or secondary education. The only association between abortion and standard of living was in the first birth order: The odds of abortion were higher among women with a medium standard of living (odds ratio, 1.5) than among women with a low standard of living. Religious affiliation was not associated with abortion in the first birth order; in the second and fourth birth orders, Muslim women had 28-38\% lower odds of abortion than did Hindu women.

For all four birth orders, women who lived in rural areas were less likely than their counterparts in urban areas to have had an abortion (odds ratios, 0.6).

\section{Open Birth Intervals}

Logistic regression revealed that the factors associated with abortions during open birth intervals (Table 3) were generally similar to those associated with abortions during 


\begin{tabular}{|c|c|}
\hline Characteristic & Odds ratio \\
\hline \multicolumn{2}{|c|}{ Maternal age at marriage } \\
\hline$<15$ (ref) & 1.00 \\
\hline $15-19$ & $1.20(1.05-1.38)^{* *}$ \\
\hline $20-24$ & $1.40(1.12-1.64)^{* * *}$ \\
\hline$\geq 25$ & $1.25(1.00-1.57)^{*}$ \\
\hline \multicolumn{2}{|l|}{ Sex of previous child } \\
\hline Male (ref) & 1.00 \\
\hline Female & $0.95(0.88-1.04)$ \\
\hline \multicolumn{2}{|l|}{ Maternal education } \\
\hline None (ref) & 1.00 \\
\hline Primary & $1.89(1.68-2.15)^{* * *}$ \\
\hline Secondary & $2.07(1.84-2.34)^{* * *}$ \\
\hline zsecondary & $1.93(1.64-2.26)^{* * *}$ \\
\hline \multicolumn{2}{|l|}{ Standard of living } \\
\hline Low (ref) & 1.00 \\
\hline Medium & $1.31(1.15-1.49)^{* * *}$ \\
\hline High & $1.69(1.45-1.97)^{* * *}$ \\
\hline \multicolumn{2}{|l|}{ Religion } \\
\hline Hindu (ref) & 1.00 \\
\hline Muslim & $0.81(0.70-0.93)^{* *}$ \\
\hline Other & $1.03(0.89-1.18)$ \\
\hline \multicolumn{2}{|l|}{ Caste } \\
\hline Scheduled caste (ref) & 1.00 \\
\hline Scheduled tribe & $0.57(0.46-0.71)^{* * *}$ \\
\hline Other backward class & $1.11(0.96-1.27)$ \\
\hline Other castes & $1.17(1.02-1.34)^{*}$ \\
\hline \multicolumn{2}{|l|}{ Residence } \\
\hline Urban (ref) & \\
\hline Rural & $0.57(0.52-0.63)^{* * *}$ \\
\hline
\end{tabular}

closed birth intervals. For example, women who were 15 or older when they married were more likely than women who married before age 15 to have an abortion during an open birth interval (odds ratios, 1.2-1.4).

The sex of the previous child was not associated with induced abortion. To examine whether such an association might exist in particular regions of India, we conducted additional analyses for each of the country's major states (not shown). Haryana was the only one of the 26 states in which the sex of the previous child was significant in the multivariate analysis; the odds of abortion were higher if the previous child was a girl than if it was a boy (odds ratio, 1.8).

Women's education was again associated with induced abortion: The odds among women who had a primary, secondary or higher education were about double (odds ratios, 1.9-2.1) those among women without any education. The odds of abortion were higher among women with a medium or high standard of living (1.3-1.7) than among those with a low standard of living.

Muslim women had odds of induced abortion 18\% lower than those among Hindu women (odds ratio, 0.8). Although caste was not associated with abortion during closed birth intervals, for open intervals women who belonged to scheduled tribes had lower odds of abortion (0.6) than did women who belonged to scheduled castes. Women who reported belonging to castes other than the scheduled or "other backward class" communities-i.e., those traditionally in a more favorable position in the caste system-had elevated odds of induced abortion (1.2). Finally, women who lived in rural areas had lower odds of induced abortion (0.6) than women in urban areas.

\section{DISCUSSION}

The present analysis is based on all reported induced abortions among a nationally representative sample of more than 90,000 ever-married women in India. At the national level, there was no association between the sex of a child and the likelihood that its mother would have an abortion the next time she became pregnant. This suggests that when other relevant factors are taken into account, sex preference is not an important driver of abortion in India.

This conclusion is consistent with qualitative studies conducted across India ${ }^{13}$ and $\mathrm{Nepal}^{14}$ that have shown that the most common reason that women seek abortions is to limit or space births, irrespective of the sex of their children. Other studies indicate that abortion is strongly associated with unintended pregnancy ${ }^{15}$ and that nonuse of contraception is the most common reason that unintended pregnancy occurs in India. ${ }^{16}$ Providing women of low parity with easy access to contraceptives and a wide choice of methods, and providing permanent methods for women of higher parities, may reduce the incidence of unintended pregnancy. This, in turn, could offset the rise in demand for abortion that may well follow from current policy and program initiatives to increase the availability of safe abortion.

It should be noted, however, that although our findings indicate that the desire for sons is not the primary reason that women in India seek abortions, this desire may nevertheless contribute to the demand for abortion in regions where prenatal sex determination technologies are widely available and the preference for sons is high. ${ }^{17}$ In a recent analysis of data from the 1998 Indian Special Fertility and Mortality Survey, Jha and colleagues observed a low female-to-male ratio among children born in $1997 .{ }^{18}$ Their conclusion, that the most likely explanation for the low sex ratio is selective abortion of female fetuses following prenatal testing, contrasts with our findings. A possible explanation is that our data included all pregnancies reported by ever-married women, thus giving a perspective over many years, whereas Jha and colleagues' analysis included only births that occurred in 1997. Our analysis did reveal the possible influence of sex selection on births in Haryana, a state in which Jha and colleagues found an exceptionally low sex ratio.

We found several factors that were associated with recourse to induced abortion. Marriage at age 15 or older was associated with increased odds of abortion for birth orders two and three and for open birth intervals, although it was not associated with abortions before the first live birth. This suggests that, regardless of their age at marriage, women typically want to have their first child as soon as possible in order to establish their social position in the family. How- 
ever, age at marriage did influence the odds of a subsequent abortion, suggesting that unintended pregnancy subsequently plays a role in the desire to obtain an abortion.

The odds of induced abortion also generally increased with older maternal age at the time of women's subsequent live birth. This suggests that the need for spacing may have triggered the decision to obtain an abortion. Consistent with this conclusion is a report that young women in the Indian state of Tamil Nadu view frequent childbirth as shameful and use abortion as a spacing method. ${ }^{19}$

Women's education was significantly associated with abortion for all closed birth orders as well as for open birth intervals. These findings, which are consistent with a review of qualitative studies conducted in India, ${ }^{20}$ could be due in part to women's need to postpone births to meet the demands of ongoing education or to take up or continue employment; the desire to limit family size in the absence of effective and accessible contraception may lead to abortion. ${ }^{21}$ Another likely factor is that educated women are more likely than uneducated women to have information about and access to abortion services. Because educational attainment and access to abortion services are both expected to increase among women in India, as a result of current national policies and programs and the country's general economic development, a rise in abortion ratios can be anticipated.

For first-order births, women with a medium standard of living were more likely than their counterparts with a low standard of living to have had an abortion. In addition, women with a medium or high standard of living were more likely than those with a low standard of living to have had an abortion during an open birth interval. This may reflect the need for women employed outside the home to postpone their first birth. For example, a study in Tamil Nadu found that women working in the pharmaceutical industry are not allowed to become pregnant. ${ }^{22}$

Although religious affiliation was not associated with abortion in the first birth order, Muslim women were less likely than Hindu women to have had abortions in the second and fourth birth orders and during open birth intervals. This may reflect both less access to and less demand for induced abortion among Muslim women owing to religious norms. Caste affiliation was not associated with abortion during closed birth intervals, perhaps because caste differentials disappeared when socioeconomic status was taken into account.

Women living in rural areas had lower odds of induced abortion than did women living in urban areas. This may reflect not only a lack of abortion services in rural areas but also a lower demand for abortion due to limited exposure to the media and to the outside world.

Our study has several limitations. First, women may not have recalled details of abortions that occurred long before the survey. During data collection, however, interviewers sought details about abortions, miscarriages and stillbirths in the context of each woman's complete birth history, an approach that is likely to enhance recall; in addition, in- terviewers were trained to ask questions that could help distinguish among induced abortions, miscarriages and stillbirths. Nonetheless, due to a variety of factors, retrospective surveys tend to underestimate the incidence of induced abortion; ${ }^{23}$ thus, it is possible that despite all efforts, some underreporting of abortions occurred in the NFHS2. Another limitation is that the survey did not include nevermarried women, whose behavior with regard to abortion could differ from that of married women.

In conclusion, our findings are consistent with the idea that unintended and unwanted pregnancy, rather than a preference for sons, has been the main driver of abortion in India. However, given recent evidence on sex ratios that may well reflect the influence of sex preference on abortion at the state or regional level, there is a need for further research on the individual-, family- and community-level factors that influence recourse to abortion.

\section{REFERENCES}

1. Ministry of Health and Family Welfare, Government of India, Medical Termination of Pregnancy Act 1971, <http://health.nic.in/ MTP\%20Act\%201971.htm>, accessed Mar. 9, 2006.

2. Ministry of Health and Family Welfare, Government of India, Maternal Health Programme, <http://mohfw.nic.in/dofw\%20website/ MATERNAL $\% 20$ HEALTH $\% 20 \% 20$ PROGRAMME\%20\%20.htm>, accessed Mar. 9, 2006

3. Khan ME et al., Abortion in India: current situation and future challenges, in: Pachauri S, ed., Implementing a Reproductive Health Agenda in India: The Beginning, New Delhi: Population Council, 1998, pp. 507-529.

4. Chhabra R and Nuna SC, Abortion in India: An Overview, New Delhi: Veerendra Printers, 1994.

5. Ministry of Health and Family Welfare, Government of India, Family Welfare Programme in India, Year Book 2001, New Delhi: Department of Family Welfare, 2003.

6. Ministry of Health and Family Welfare, Government of India, op. cit. (see reference 2).

7. Bairagi R, Effects of sex preference on contraceptive use, abortion and fertility in Matlab, Bangladesh, International Family Planning Perspectives, 2001, 27(3):137-143.

8. Arnold F, Kishor S and Roy TK, Sex-selective abortions in India, Population and Development Review, 2002, 28(4):759-785.

9. Booth BE, Verma M and Beri RS, Fetal sex determination in infants in Punjab, India: correlations and implications, BMJ, 1994, 309(6964): 1259-1261.

10. Ganatra B and Hirve S, Induced abortions among adolescent women in rural Maharashtra, India, Reproductive Health Matters, 2002, 10(19): 76-85.

11. Ravindran TK and Balasubramanian P, "Yes" to abortion but "no" to sexual rights: the paradoxical reality of married women in rural Tamil Nadu, India, Reproductive Health Matters, 2004, 12(23):88-99.

12. International Institute for Population Sciences (IIPS) and ORC Macro, National Family Health Survey (NFHS-2), 1998-1999, Mumbai, India: IIPS, 2000.

13. Visaria L et al., Abortion in India: emerging issues from qualitative studies, Economic and Political Weekly, 2004, 39(46-47):5044-5052; Ravindran TK and Balasubramanian P, 2004, op. cit. (see reference 11); and Ganatra B and Hirve S, 2002, op. cit. (see reference 10).

14. Thapa $S$ and Padhye SM, Induced abortion in urban Nepal, International Family Planning Perspectives, 2001, 27(3):144-147 \& 151.

15. Visaria L et al., 2004, op. cit. (see reference 13).

16. Ibid. 
17. Bairagi R, 2001, op. cit. (see reference 7).

18. Jha $\mathrm{P}$, et al., Low female-to-male sex ratio of children born in India: national survey of 1.1 million households. Lancet, 2006, 367(9524): 211-218.

19. Visaria L et al., 2004, op. cit. (see reference 13).

20. Ibid.

21. Marston C and Cleland J, Relationships between contraception and abortion: a review of the evidence, International Family Planning Perspectives, 2003, 29(1):6-13.

22. Visaria L et al., 2004, op. cit. (see reference 13).

23. Rossier C, Estimating induced abortion rates: a review, Studies in Family Planning, 2003, 34(2):87-102.

\section{RESUMEN}

Contexto: La preferencia por los hijos varones en la India puede ser un factor que impulsa a las mujeres con fetos del sexo femenino a someterse a abortos inducidos. Para evaluar esta hipótesis, es necesario disponer de más información sobre la incidencia del aborto y los factores maternos y sociales que están asociados con este procedimiento.

Métodos: Se calcularon las razones de abortos por orden de nacimiento utilizando las datos sobre los nacimientos de 90.303 mujeres alguna vez casadas de 15-49 años de edad, que participaron en la National Family Health Survey de 1998-1999 realizada en la India. Con respecto a los cuatro primeros nacimientos, se evaluó la relación entre el aborto y las diversas variables maternas y sociales, incluido el sexo del último hijo de la mujer, mediante el uso de análisis de regresión logística.

Resultados: La razón global de abortos fue de 17,0 abortos por cada 1.000 embarazos. Dicha razón aumentó de 5,3 por cada 1.000 embarazos de primer orden hasta 25,8 por cada $1.000 \mathrm{em}$ barazos de tercer orden, y luego disminuyó. La variable de predicción del aborto más sólida fue la educación de la madre: las mujeres que habían cursado por lo menos instrucción primaria eran más proclives que aquellas que carecían totalmente de instrucción a haberse sometido a un aborto (razones de momios, 1,9-6,7). Las que residian en zonas rurales presentaban una menor probabilidad de haber tenido un aborto $(0,6)$. No se registró una relación entre el sexo del hijo o hija anterior y las probabilidades de que luego la mujer se sometiera a un aborto.

Conclusión: A nivel nacional, es probable que los embarazos no planeados, en vez del sexo del hijo o hija anterior, sean la causa probable por la cual se recurre a un aborto en la India. El logro de un mayor nivel educativo entre las mujeres puede conducir a un aumento de la demanda del aborto.

\section{RÉSUMÉ}

Contexte: La préférence culturelle des enfants de sexe masculin peut être un facteur de recours à l'avortement en Inde, les femmes enceintes de fotus féminins pouvant décider d'interrompre leur grossesse. L'évaluation de cette hypothèse exige une information plus complète sur l'incidence de l'avortement et sur les corrélats maternels et sociaux de la procédure.

Méthodes: Les rapports d'avortement par ordre de naissance ont été calculés en fonction des antécédents de naissances de 90.303 femmes de 15 à 49 ans, mariées ou l'ayant jamais été, ayant participé à l'Enquête nationale sur la santé familiale menée en Inde en 1998-1999. Pour les quatre premières naissances, l'association entre l'avortement et diverses variables maternelles et sociales, y compris le sexe du dernier enfant de la répondante, a été évaluée par régression logistique.

Résultats: Le rapport d'avortement global a été calculé à 17,0 pour mille grossesses. Ce rapport passe de 5,3 pour mille grossesses pour les naissances de premier rang à 25,8 pour les naissances de troisième rang, avant de décliner aux rangs suivants. L'éducation maternelle s'est avérée le plus fort prédicteur d'avortement. Les femmes instruites, pour le moins, au niveau primaire se sont révélées plus susceptibles que celles non scolarisées d'avoir recouru à l'avortement (rapport de probabilités, 1,9-6,7). La résidence rurale est apparue associée à une probabilité d'avortement réduite $(0,6)$. Aucune association n'est apparue entre le sexe de l'enfant précédent d'une femme et la probabilité qu'elle se soit ensuite fait avorter.

Conclusion: Au niveau national, il est probable que la grossesse non planifiée, plutôt que le sexe de l'enfant précédent, préside à la demande d'avortement en Inde. L'éducation croissante des femmes pourrait mener à un accroissement aussi de la demande d'avortement.

\section{Acknowledgment}

This study was funded by the UK Department for International Development via the Opportunities and Choices program on reproductive health, based at the University of Southampton.

Author contact: r.w.stones@soton.ac.uk 